\title{
ELViS is in the Building: The European Loans and Visits System and first experiences with Transnational and Virtual Access
}

\author{
Sharif Islam $¥, \S$, Helen Hardyl, Scott Wilson' \\ $\ddagger$ Naturalis Biodiversity Center, Leiden, Netherlands \\ $\S$ DiSSCo, Leiden, Netherlands \\ | Natural History Museum, London, United Kingdom
}

Corresponding author: Sharif Islam (sharif.islam@naturalis.nl)

Received: 15 Sep 2021 | Published: 16 Sep 2021

Citation: Islam S, Hardy H, Wilson S (2021) ELViS is in the Building: The European Loans and Visits System and first experiences with Transnational and Virtual Access. Biodiversity Information Science and Standards 5 : e75312. https://doi.org/10.3897/biss.5.75312

\section{Abstract}

The European Loans and Visits System (ELViS), a DiSSCo e-service in development, will be a one-stop shop for global scientific users to access the Natural Science Collections in Europe. This talk provides a summary of important milestones: the release of version 1.0 of ELViS (released on March 18, 2021) and an analysis of the feedback received from the access providers and scientific users (over 500 submissions were received). ELViS 1.0 was used to facilitate the 3rd Transnational Access (to fund short-term research visits to consortium institutions) and the 2nd Virtual Access call (to fund digitisation-on-demand requests) for SYNTHESYS+ (a European Commission funded project to develop European collections infrastructure). This milestone is the culmination of activities in SYNTHESYS+ with partners consisting of researchers and staff members of several museums and herbaria across Europe and a commercial partner, Picturae (a Dutch company specialising in collections digitisation and preservation services for the cultural heritage and archival sectors).

The talk starts with a brief summary of the activities and behind the scenes planning processes that went into ensuring a smooth transition from the existing SYNTHESYS+ transnational access portal to the new ELViS system. These activities included weekly 
meetings, testing, bug fixing, coordinating with transnational and virtual access coordinators from different institutions, and wireframe design. The talk also focuses on specific aspects of the data elements that enabled the call and the application process with examples of using persistent identifiers for people, institutions and facilities. The concepts behind these data elements and identifiers were based on the blueprint of the DiSSCo architecture. The talk concludes with lessons learned and issues discovered and a brief look into the future plans and upcoming milestones for ELViS.

\section{Keywords}

Transnational Access, Virtual Access, natural science collections, DiSSCo, collectionsbased research, collections, specimens, SYNTHESYS+

\section{Presenting author}

Sharif Islam

\section{Presented at}

TDWG 2021

\section{Funding program}

H2020-INFRAIA-2018-2020

\section{Grant title}

\section{SYNTHESYS PLUS}

